\title{
EVOLUÇÃO DA LINHA DE COSTA NO FLANCO NORTE DO DELTA DO RIO PARAÍBA DO SUL (RJ) A PARTIR DE REGISTROS HISTÓRICOS
}

\author{
André Paulo Ferreira da Costa ${ }^{(a)}$, Thaís Baptista da Rocha ${ }^{(b)}$ \\ (a) Instituto de Geografia, Universidade do Estado do Rio de Janeiro, Email: dacostaandre01@ gmail.com \\ (b) Departamento De Geografia, Universidade Federal Fluminense, Email: thaisitc5@yahoo.com.br
}

\section{Eixo: DINÂMICA E GESTÃO DE ZONAS COSTEIRAS}

\begin{abstract}
Resumo
A planície deltaica do Rio Paraíba do Sul representa uma área extremamente dinâmica onde se verificam alterações proeminentes na linha de costa. Por esse motivo, o delta vem sendo alvo de estudos sistemáticos desde a primeira metade do século XX. Alberto Ribeiro Lamego foi um dos pioneiros nesses estudos, deixando obras de grande importância para a área. $\mathrm{O}$ presente trabalho teve por objetivo avaliar a evolução da linha de costa no flanco Norte do delta do Rio Paraíba do Sul a partir de registros obtidos na obra de Lamego $(1934 ; 1945 ; 1946)$ em conjunto com outros registros históricos diversos, fotografias e imagens. Foi possível observar progradação da ordem de $740 \mathrm{~m}$ em um determinado ponto da área de estudos com nítida tendência de aumento das taxas de progradação em direção a norte. Mostramos a pertinência do uso de registros históricos em estudos relacionadas a geomorfologia costeira e, em particular, ao delta do Rio Paraíba do Sul.
\end{abstract}

Palavras chave: Evolução linha de costa, delta Paraíba do Sul, registros históricos.

\section{Introdução}

O emprego de registros históricos é particularmente valioso para o entendimento de processos geomorfológicos em curso. O uso de tais registros, obtidos a partir de imagens, fotografias e livros antigos, nos permite contemplar as mudanças ambientais processadas em escala histórica, tornando possível a qualificação e a quantificação dessas mudanças. Isto é interessante, pois, diferentemente de pesquisas realizadas em escala geológica, traz à luz mudanças ambientais ocorridas sob influência antrópica, podendo orientar de forma mais precisa políticas de planejamento ambiental (TRIMBLE, 2008; TRIMBLE \& COOKE, 1991).

Segundo Trimble (2008), diversos trabalhos utilizam essa abordagem e variados são seus enfoques. Entretanto, grande parte desses trabalhos se concentra em temas relacionados à Geomorfologia Costeira e Fluvial. Por exemplo, Ren \& Shi (1986), utilizando dados históricos de vazão/carga sedimentar, imagens e registros históricos de migração de foz, mostrou a evolução da linha de costa atrelada ao crescimento do delta do Rio Amarelo, China. 
A planície deltaica do Rio Paraíba do Sul, localizada no Norte Fluminense, cuja evolução está atrelada a processos fluviais e costeiros, representa uma área extremamente dinâmica onde se verificam alterações proeminentes na linha de costa (ROCHA, 2009). Atualmente, o delta experimenta uma fase na qual se verifica franca progradação nas localidades de Gargaú e Grussaí e vigorosa erosão na localidade de Atafona. Alguns trabalhos expõem essas tendências fazendo uso de dados históricos. Fernandez \& Rocha (2015), mediante realização de monitoramentos topográficos entre os anos de 2008-2014, verificaram acreção de 80 m em Gargaú, resultando numa taxa de progradação aproximada de $12 \mathrm{~m} / \mathrm{ano}$. Por outro lado, Ribeiro \& Rosas (2006), fazendo uso de uma série histórica de fotografias aéreas entre os anos de 1954-2005, calculou taxa de erosão de cerca de 7,8m/ano em locais críticos de Atafona.

Frente à sua relevância e ao interesse científico que desperta, o delta do Rio Paraíba do Sul vem sendo alvo de estudos sistemáticos desde a primeira metade do século XX. O geólogo e engenheiro de minas Alberto Ribeiro Lamego foi um dos pioneiros nesses estudos, deixando obras de grande importância para a Geografia fluminense (FREITAS, 2007; FREITAS et al., 2006). Dentre as obras deixadas por eles, se destacam "O Homem e o Brejo" e "O Homem e a Restinga", e "A Planície do Solar e da Senzala". Estas obras contêm mapas, fotografias, esquemas, perfis geológicos e descrições que testemunham a evolução do delta do Rio Paraíba do Sul durante o passado recente. Esses registros, embora valiosos, ainda são pouco explorados. Nesse sentido, o presente trabalho tem por objetivo avaliar a evolução da linha de costa no delta do Rio Paraíba do Sul a partir de registros obtidos na obra de Lamego em conjunto com outros registros históricos obtidos no blog Museuonlinesfi, imagens recentes e antigas.

\section{Materiais e Métodos}

Visando delimitar todas as feições presentes em nossa área de estudo, foi realizado o mapeamento das feições geomorfológicas presentes na área em escala local 1:40.000 com base em imagem de satélite ALOS pancromática (resolução espacial de 5m) do ano de 2008. As feições foram vetorizadas sobre a imagem através do Software ArcGIS 10.1, gerando mapa geomorfológico onde foram identificadas feições de cristas de praia, depressões, manguezais, corpos hídricos, área urbana e barreiras arenosas. Sobre este mapa geomorfológico foi vetorizada através do ArcGIS 10.1 a paleolinha de costa referente ao ano de 1926. Esta paleolinha foi obtida a partir da interpretação de registros históricos extraídos da obra de Alberto Lamego e no blog da internet Museuonlinesfi que busca preservar a história de Gargaú. A linha foi estabelecida seguindo-se a margem interna da Lagoa Velha e a direção da Rua da Lagoa.

Similarmente, com base em uma fotografia aérea georeferenciada (resolução espacial aproximada de $4 \mathrm{~m}$ ) do ano de 1954, foi realizada a vetorização e delimitação da linha de costa referente àquele ano através do ArcGIS 10.1. A linha de costa referente a 2016 foi determinada por caminhamento com GPS Garmin

DOI - 10.20396/sbgfa.v1i2017.2177 - ISBN 978-85-85369-16-3 
GPSMAP64S. Foi realizado caminhamento por toda a extensão da barreira arenosa que se localiza a frente da lagoa de Gargaú, demarcando-se a linha da crista da berma, a qual coincide com a linha de avanço máximo das ondas. A linha foi integrada ao mapa geomorfológico através do ArcGIS 10.1.

\title{
3. Resultados e discussão
}

Consta na obra "A Planície do Solar e da Senzala" de Lamego (1934) o primeiro registro acerca do processo de progradação do flanco norte do delta do Rio Paraíba do Sul. Lamego relata:

\begin{abstract}
"A misteriosa origem das restingas desvendou-se-nos com um fenômeno maremático, ocorrido em Gargaú, em 1926, que salteando a pequena vila de improviso, privou-a de sua praia. Ao soprar de uma violenta suestada foram os vagalhões trazendo as massas silicosas. E do Pontal da Convivência - na foz do Paraíba - veio estirando-se para o norte uma lingueta de areia, de cem metros de largo por dois de alto, paralela à costa primitiva. De permeio, afundou-se uma laguna idêntica em largura, retilínea por quatro quilômetros de extensão. Quer isto dizer que o oceano recuou duzentos metros no curto espaço de semanas!" (p. 18-19).
\end{abstract}

Registro este reforçado anos mais tarde na publicação "O homem e o brejo" (1945). Estes registros encontram suporte quando confrontados com fotografias e informações extraídas do blog Museuonlinesfi. Neste blog encontramos fotografias e relatos que mostram a Lagoa Velha de Gargaú e as antigas casas de praia desde o ano de 1939. Como resultado da análise conjunta de tais registros obtivemos a paleolinha de costa referente ao ano de 1926 (Figura 1c). Esta linha foi delimitada seguindo a margem interna da Lagoa velha e a direção da Rua da Lagoa, a qual anteriormente representava o arruamento final em frente à praia de Gargaú.

Muito embora os critérios adotados não garantam precisão na delimitação da paleolinha de costa de 1926, ao calcular as taxas de acreção da planície no ponto de maior distância entre as linhas de 1926-1954 e as linhas 1954-2016 (figura 1c), encontramos respectivamente taxas de 8,4m/ano e 8,1m/ano. Partindo da premissa que os processos de sedimentação e progradação da planície não tenham se alterado substancialmente durante esse período, a proximidade desses valores é um indicativo de que a paleolinha referente ao ano de 1926 é uma aproximação confiável.

Além disso, calculamos taxa de retrogradação da barreira arenosa entre os anos de 2008 e 2016 no mesmo ponto utilizado para os cálculos anteriores. Os cálculos mostraram recuo da linha de costa da ordem de $150 \mathrm{~m}$, representando uma taxa de retrogradação aproximada de 18,7m/ano. Foram realizados os mesmos cálculos no ponto de maior distância entre as linhas de 2008 e 2016 (figura 1c). Os cálculos mostraram recuo da ordem de $200 \mathrm{~m}$ neste ponto, representando taxa de retrogradação de $25 \mathrm{~m} /$ ano. Isto se verifica, 


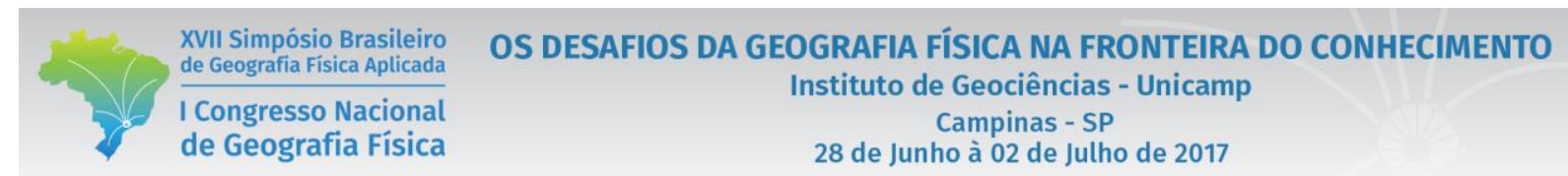

pois, após emergir, a barreira apresenta baixa altimetria facilitando o mecanismo de transposição de ondas - overwash. Este processo de retrogradação promovido pela transposição de ondas é uma das etapas que levam a incorporação da barreira a planície deltaica e a sua consequente progradação, conforme proposto por Vasconcelos et al. (2016).

Vasconcelos et al. (2016) encontrou em perfis de praia localizados nos pontos 1 e 2 da figura 1c retrogradação da ordem de 40 e 80 m entre os anos de 2008 e 2015, resultando respectivamente em taxas de retrogradação de 5,7m/ano e 11,4m/ano. A despeito dos métodos adotados em cada trabalho, a diferença entre os valores encontrados mostra que, em direção ao fim da área de influência de emersão de barreiras, as taxas de retrogradação da barreira decrescem vigorosamente. A observação das linhas de costa referentes aos anos de 2008 e 2016 na figura 1c endossa esta afirmativa, mostrando que, em direção a norte da área de estudos, ambas se aproximam progressivamente até se encontrarem.

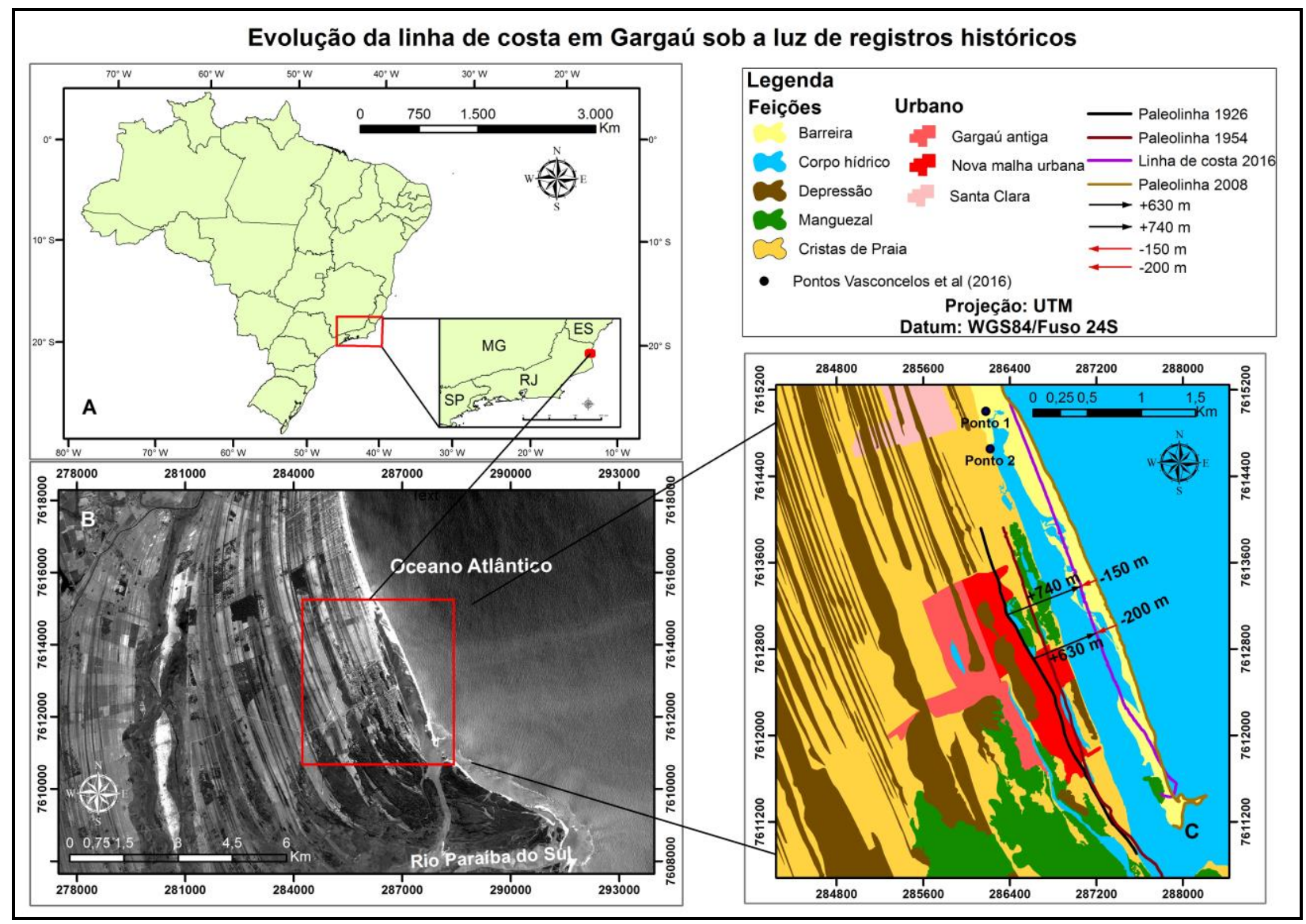

Figura 1 - A e B) Localização da Área de estudo. Imagem ALOS 2008. C) Mapa geomorfológico de Gargaú obtido a partir da imagem ALOS 2008 com as paleolinhas de costa indicadas. 


\section{Considerações finais}

O presente trabalho traz contribuições para o entendimento da evolução recente da linha de costa no flanco norte do delta do Rio Paraíba do Sul a partir dos registros históricos explorados. Foi possível observar progradação máxima da ordem de 740 m entre 1926 e 2016 e retrogradação máxima de $200 \mathrm{~m}$ entre 2008 e 2016. Estes resultados mostram, em concordância ao modelo proposto por Vasconcelos et al (2016), que a despeito das altas taxas de retrogradação calculadas para a barreira arenosa, a resultante final para a planície deltaica é de progradação.

Os resultados suscitam a necessidade de se aprofundar as pesquisas em busca de outros registros históricos que testemunhem a emersão e a evolução das barreiras arenosas a partir de 1926. Contudo, mostramos a pertinência da adoção deste tipo de dado em estudos relacionadas a geomorfologia costeira e, em particular, ao delta do Rio Paraíba do Sul. Esperamos, com isso, estimular o uso desta abordagem em pesquisas relacionadas a esses temas.

\section{REFERÊNCIAS}

FERNADEZ, G. B. \& ROCHA, T. B. da. Barreiras costeiras holocênicas: geomorfologia e arquitetura deposicional no litoral do rio de janeiro. Revista Brasileira de Geomorfologia, São Paulo, vol.16, n.2, (Abr-Jun) p.301-319, 2015.

FREITAS, I. A. de. História Ambiental e Geografia: Natureza e cultura em interconexão. Geo Uerj, Rio de Janeiro, Vol. 2, n. 17, p. 20-33, 2007.

FREITAS, I. A. de; PINTO, F. L. M. \& MOURA, R. de A. A História Ambiental na Geografia de Alberto Lamego. Interagir: Pensando a extensão, Rio de Janeiro, n. 9, p. 71-78, jan/jul. 2006.

LAMEGO, Alberto Ribeiro. A Planície do Solar e a Senzala. Rio de Janeiro: Livraria Católica, 1934.

LAMEGO, Alberto Ribeiro. O Homem e a Restinga. Rio de Janeiro, IBGE, 1946.

LAMEGO, Alberto Ribeiro. O Homem e o Brejo. Conselho nacional de geografia, 1945.

MUSEUONLINESFI. <http://museuonlinesfi.blogspot.com.br/search?q=Garga\%C3\%BA\&updated-max=2015-0521T06:57:00-07:00\&max-results=20\&start=0\&by-date=false >. Acessado em 02/2017.

REN, M-E. \& SHI, Y-L. Sediment discharge of the Yellow River (China) and its effect on the sedimentation of the Bohai and the Yellow Sea. Continental Shelf-Research, Vol. 6, n. 6, pp. 785--810, 1986. 
RIBEIRO, G. P.; ROSAS, R. O. Processos costeiros: erosão em Atafona e progradação em Grussaí, São João da Barra (RJ) - morfometria para retratação espacial desses eventos e identificação de sua tendência evolutiva. In: VI SIMPÓSIO NACIONAL DE GEOMORFOLOGIA, GOIÂNIA, Anais, 2006.

ROCHA, T. B. (2009). Morfodinâmica costeira e gestão de orla marítima em costa sob influência fluvial: borda meridional do atual delta do Rio Paraíba do Sul (RJ). Dissertação (Mestrado em Geografia): Inst. Geociências/Universidade Federal Fluminense. 141p.

VASCONCELOS, S. C. de; ROCHA, T. B. da; PEREIRA, T.; ALVES, A. R. \& FERNANDEZ, G. B. Gênese e morfodinâmica das barreiras arenosas no flanco norte do delta do Rio Paraíba do Sul (RJ). Revista brasileira de Geomorfologia, Vol. 17, n. 3, p. 481-498, 2016.

TRIMBLE, S. W \& COOKE, R. U. Historical sources for geomorphological research in the United States. The Professional Geographer, Vol. 43, n. 2, p. 212-228, 1991.

TRIMBLE, S. W. The use of historical data and artifacts in geomorphology. Progress in Physical Geography, Vol. 32, n. 1, p. 3-29, 2008. 